\title{
Numerical Analysis of Settlement Response of Shallow Footing Subjected to Heavy Rainfall and Flood Events
}

\author{
Nadarajah Ravichandran, Tharshikka Vickneswaran, \\ Siddharth Marathe, Vishnu Saketh Jella \\ Glenn Department of Civil Engineering, Clemson University, Lowry Hall, Clemson, US \\ Email:nravi@clemson.edu, tvickne@g.clemson.edu, sjmarat@clemson.edu,vjella@g.clemson.edu
}

How to cite this paper: Ravichandran, N., Vickneswaran, T., Marathe, S. and Jella, V.S. (2021) Numerical Analysis of Settlement Response of Shallow Footing Subjected to Heavy Rainfall and Flood Events. International Journal of Geosciences, 12, 138-158. https://doi.org/10.4236/ijg.2021.122009

Received: January 20, 2021

Accepted: February 21, 2021

Published: February 24, 2021

Copyright $\odot 2021$ by author(s) and Scientific Research Publishing Inc. This work is licensed under the Creative Commons Attribution International License (CC BY 4.0).

http://creativecommons.org/licenses/by/4.0/

(c) (i) Open Access

\begin{abstract}
The US and many parts around the world have experienced prolonged periods of heavy rainfall, severe floods, and droughts over the past 50 years. This study investigates the impacts of extreme hydrological events such as heavy rainfall and flood on the settlement behavior of continuous footing installed in unsaturated soil using a coupled Geotechnical-Hydrological finite element software, PLAXIS 2D. Initially, the effect of different degrees of saturation on the settlement behavior of the continuous footing of widths $1.5 \mathrm{~m}$, $3.0 \mathrm{~m}$, and $4.5 \mathrm{~m}$ was analyzed by applying a mechanical load. Then the settlement behavior of the footing was analyzed by applying heavy rainfall of intensity $102 \mathrm{~mm} /$ day for six days. Finally, the settlement behavior of the footing was analyzed by applying a flood head of 2.5 meters for seven days. The results indicated that the wetting front movement during heavy rainfall and flooding led to the weakening of soil strength and stiffness and induced additional settlements. The additional settlement induced by the flood was significantly higher than the heavy rainfall. The differential settlement was higher when the rainfall was applied on one side of the footing. The rebound of the elastic settlement was uniquely noticed when the flood head receded with time. The results indicated that not all the settlements were induced by the soil saturation but also due to the hydrostatic loading due to the flood head. The settlements induced by the flooding exceeded the allowable settlement of $25 \mathrm{~mm}$, resulting in failure. These additional settlements caused by heavy rainfall and flood will lead to poor serviceability of the structures and cause the failure of the footing.
\end{abstract}

\section{Keywords}

Coupled Flow Deformation, Unsaturated Soils, Shallow Footings, Heavy 
Rainfall, Flood, Drought

\section{Introduction}

According to the United States Geological Survey (USGS), Extreme hydrological events such as heavy rainfall, flood, and drought have become frequent in recent years. These events not only affect the lives of humans, animals, and crops but also the performance of the infrastructures. The impacts of these extreme hydrological events have caused substantial damages to the superstructures. Among them, the 2014 New York flood, the 2015 Missouri flood, the 2016 Oklahoma flood, and Louisiana flood, and the 2017 California flood and Houston flood are some examples of severe floods that occurred in recent years. The impacts of these extreme events on the performance of the footings that support various structures such as bridges, buildings, and earth dams and levees are ignored. The current loss estimation schemes ignore the damages caused by footing failures (bearing capacity and settlement) induced by extreme hydrological events.

Shallow footings are the simplest and most economical footing type used for supporting small to medium size structures. The shallow footings transfer the loads to the near-surface unsaturated soils that fluctuate with hydrological events. Recent developments in unsaturated soil mechanics show that the strength and settlement parameters of the soils are greatly influenced by the matric suction that greatly influences the strength and settlement parameters of the soils. Shallow footings have been located, constructed on near surface unsaturated soils, ignoring the effect of matric suction that affects the shear strength of the soil [1]-[6]. Only a few studies have been conducted to analyze the effect of rainfall infiltration on the stability of the shallow footing due to the difficulties in determining the strength and deformation parameters as functions of matric suction and/or Degree of Saturation (DoS). Spatial and temporal variation of the Degree of Saturation (DoS) of the soil is directly influenced by various hydrological parameters, especially water table depth, infiltration, flood, and drought. These hydrological events are site-specific and vary with time. Therefore, the effects of hydrological events must be incorporated for the safe and economical design of shallow footings.

The geotechnical design of footing involves adjusting the size and depth of the footing until it meets both bearing capacity and the settlement criteria. Among these two criteria, the settlement criterion usually controls the design of shallow footings. Both the bearing capacity and settlement analysis theories used in the current practice are based on the assumption that the soil is either dry or fully saturated. Therefore, the near-surface soil saturation within the influence zone of the shallow footing varies significantly due to hydrological events (heavy rainfall and/or flooding). Also, several unsaturated soil mechanics principles-based 
bearing capacity and settlement equations have been proposed by many researchers in recent years for analytical design [1] [2] [3]. Mahmoudabadi and Ravichandran 2019 proposed a novel procedure that considers the site-specific historical rainfall and water table data in the design of the shallow footing. Their study showed that matric suction increased the ultimate bearing capacity of the footing by almost $230 \%$ of the bearing capacity compared with the fully saturated condition. Also, the elastic settlement of various footings has been decreased to approximately $87 \%$ and $40 \%$ of the settlement considering fully saturated conditions. These studies concluded that the bearing capacity and settlement analysis could be performed better, and the cost of construction could be reduced if the site-specific hydrological parameters are considered in the design of the shallow footing using unsaturated soil mechanics.

This research aims to investigate the effects of heavy rainfall and flooding on the settlement behavior of shallow footings using a coupled flow-deformation finite element computer program, PLAXIS 2D. The settlement behavior of three continuous footings with a width of $1.5 \mathrm{~m}, 3.0 \mathrm{~m}$, and $4.5 \mathrm{~m}$ were analyzed by applying site-specific heavy rainfall and flood. The details of the analysis procedure and the results are presented below.

\section{Coupled Flow-Deformation Analysis Using PLAXIS 2D}

Accurately predicting the behavior of the footing subjected to various hydrological loadings using finite element method requires coupling the flow and deformation behavior at the governing equation level. This is because the flow of water affects the deformation of the soil and vice versa. In this study, the finite element software PLAXIS 2D, a reliable Geotechnical-Hydrological finite element software widely used by practicing engineers and academics, was used to investigate the settlement behavior of continuous footing subjected to heavy rainfall and flooding.

\subsection{Deformation Analysis Theory for Unsaturated Soils}

Expressing the effective stress in unsaturated soils as a function of the DoS is essential for accurately modeling soil deformation behavior under hydrological events. Among the many equations used to represent the effective stress of unsaturated soils, the Bishop's effective stress equation was used in this study. Equation (1) shows Bishop's effective stress $(\sigma)$ calculation which relies on the total stress $(\sigma)$, atmospheric pressure $(P a)$, pore water pressure $\left(P_{W}\right)$, and the suction coefficient $(\chi)$. PLAXIS 2D assumes $P a$ to be zero and $\chi$ is set equal to the effective saturation. This distinction transformation during the fully coupled deformation analyses is also shown in Equation (1). The transformed equation relies on the effective saturation $\left(S_{\text {eff }}\right.$ Equation $\left.(2)\right)$, steady-state pore water pressure $\left(P_{\text {steady }}\right)$ and excess pore water pressure $\left(P_{\text {excess }}\right)$ to define the active pore water pressure $\left(P_{\text {active }}\right)$. 


$$
\begin{gathered}
\sigma^{\prime}=\sigma-P_{a}+\chi\left(P_{a}-P_{w}\right)=\sigma-S_{\text {eff }} *\left(P_{\text {steady }}-P_{\text {excess }}\right)=\sigma-P_{\text {active }} \\
S_{\text {eff }}=\frac{S-S_{\text {res }}}{S_{\text {sat }}-S_{\text {res }}}
\end{gathered}
$$

where $S_{\text {res }}$ is the residual DoS and $S_{\text {sat }}$ is the saturated DoS.

The $P_{\text {steady }}$ was automatically calculated by PLAXIS 2D based on a preliminary steady-state groundwater flow (PLAXIS 2D 2015). The $S_{\text {eff }}$ is influenced by the wetting front induced by the hydrological loadings and changed from less than 1.0 (partially saturated) to 1.0 (fully saturated). The value of $P_{\text {active }}$ increases and reduces the vertical effective stress $(\sigma)$ when $S_{\text {eff }}$ is equal to 1.0 (fully saturated) at each node. Decrease in $\sigma$ ) at fully saturated state reduces the confining pressure $\left(\sigma_{3}^{\prime}\right)$. Since the elastoplastic constitutive model utilized in this study uses $\sigma_{3}^{\prime}$ to define the upper limits of the stress-strain curve, the upper-stress limits of the curve were lowered, and the stiffness of the soil material was decreased upon saturation. The fully coupled flow-deformation analyses phase calculated the change in DoS, effective vertical stress, and confining pressure with time and continuously updated the stress-strain model and deformations simultaneously. Once the simulation was complete, the deformations, DoS, and suction were measured.

Equation (3) shows the coupled finite element equation implemented in PLAXIS 2D for capturing the deformation of the soil body as expressed in standard solid mechanics notations.

$$
\left[\begin{array}{cc}
\underline{\underline{K}} & \underline{\underline{Q}} \\
\underline{\underline{C}} & -\underline{\underline{S}}
\end{array}\right]\left[\begin{array}{c}
\frac{\mathrm{d} \underline{v}}{\mathrm{~d} t} \\
\frac{\mathrm{d} \underline{p}_{w}}{\mathrm{~d} t}
\end{array}\right]=\left[\begin{array}{ll}
0 & 0 \\
0 & \underline{\underline{H}}
\end{array}\right]\left[\begin{array}{c}
\underline{\underline{p}} \\
\underline{p}_{w}
\end{array}\right]=\left[\begin{array}{c}
\mathrm{d} f_{u} \\
\mathrm{~d} t \\
\underline{G}+\underline{q}_{p}
\end{array}\right]
$$

where $\underline{\underline{K}}$ is the stiffness matrix, $\underline{v}$ is the nodal values of the displacements, $\underline{Q}$ is the coupling matrix, $\underline{p}_{w}$ is the pore water pressure, $\underline{f}_{u}$ is the increment $\overline{\overline{\text { of }}}$ the load vector, is the $\underline{\underline{H}}$ is the permeability matrix, $\underline{\underline{G}}$ is a vector in which effect of gravity on flow in the vertical direction is considered, $\underline{q}_{p}$ is the flux on boundaries, $\underline{\underline{C}}$ is the coupling matrix, and $\underline{\underline{S}}$ is the compressibility matrix.

\subsection{Flow Analysis Theory for Unsaturated Soils}

The water flow in the porous medium is represented by Darcy's law in standard continuum mechanics notations, as shown in Equation (4).

$$
q=\frac{k}{\rho_{w} g}\left(\nabla \rho_{w}+\rho_{w} g\right)
$$

where $q$ is the specific discharge, $k$ is the tensor of permeability, $g$ is the acceleration due to gravity, and $\rho_{w}$ is the density of water.

\subsection{Coupling Deformation and Flow Behaviors}

As shown in Equations (1) and (2), the effective stress which governs the mechanical behavior of unsaturated soils (shear strength and volume change) is af- 
fected by the matric suction. The matric suction is directly related to the DoS of the soil through the soil water characteristic curve (SWCC). In other words, depending on the movement of moisture (change in the DoS), the soil deformation will be affected. As the DoS changes, the flow rate of water through unsaturated soil will also change as the relative permeability is a function of the DoS.

\subsection{Constitutive Model and Model Parameters}

An elastoplastic constitutive model must be used to accurately predict the settlement behavior of the footing as the soils show nonlinear elastoplastic stress-strain behavior even at the low strain levels. Among the many constitutive models available in PLAXIS 2D, the Hardening Soil (HS) model was used in this study. The HS model is an elastoplastic model that considers the modulus reduction with strain reasonably well compared to the simplest and widely used linear-elastic perfectly plastic Mohr-Coulomb model. The schematic of the HS model is shown in Figure 1 (PLAXIS 2D 2015). The influence of strain on the modulus is represented by a parameter called power function $(m)$. The key input parameters for the HS model are the secant modulus of the failure stress $\left(E_{50}^{\text {ref }}\right)$, the tangent modulus for primary oedometer loading $\left(E_{\text {oed }}^{\text {ref }}\right)$, and the unloading/ reloading modulus $\left(E_{u r}^{r e f}\right)$ to define the shape and curvature of the stress-strain hyperbola. The basic properties and HS model parameters used in this study are shown in Table 1 (Duneman et al. 2015). An integral part of this study was to vary the initial DoS to simulate various levels of drought conditions prior to the application of heavy rainfall and flood. The moist unit weights of the soil body were calculated using the corresponding initial DoS to compute the initial stresses numerically in PLAXIS 2D.

\subsection{Hydraulic Model and Model Parameters}

Among the many SWCC's available in the literature, the model proposed by van Genuchten (1980) was used in this study to relate the DoS to the suction and to calculate the relative permeability. This SWCC model captures the DoS-suction

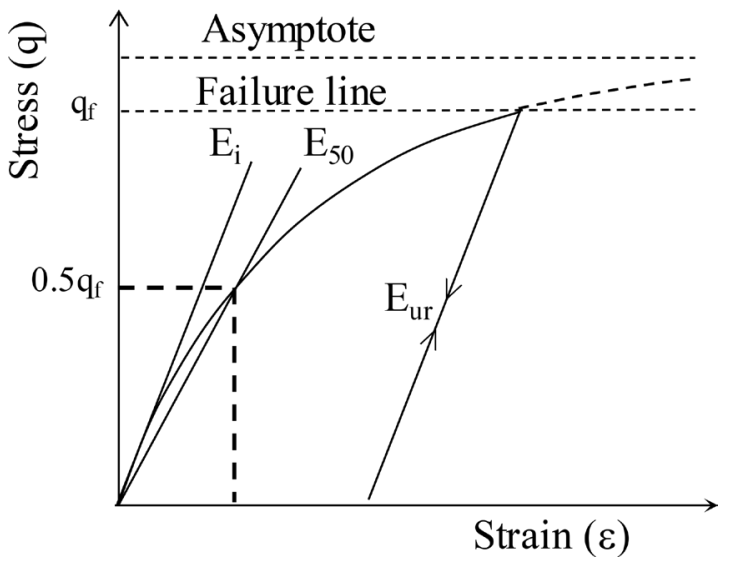

Figure 1. Schematic of the stress-strain behavior of the Hardening Soil model in deviatoric stress-axial strain space. 
Table 1. Soil properties.

\begin{tabular}{cc}
\hline Parameter & Value \\
\hline $\begin{array}{c}\text { Dry unit weight, } \gamma_{d}\left(\mathrm{kN} / \mathrm{m}^{3}\right) \\
\text { Saturated unit weight, } \gamma_{\text {sat }}\left(\mathrm{kN} / \mathrm{m}^{3}\right)\end{array}$ & 15.40 \\
Void ratio, $e$ & 19.45 \\
Effective friction angle, $\phi^{\prime} \quad($ deg. $)$ & 0.70 \\
Dilatancy angle, $\psi($ deg. $)$ & $31^{\circ}$ \\
Effective cohesion, $c^{\prime}(\mathrm{kPa})$ & $1^{\circ}$ \\
Reference stiffness modulus, $E_{50}^{\text {ref }} \quad(\mathrm{kPa})$ & 0 \\
Reference modulus for unloading and reloading, $E_{\text {ur }}^{\text {ref }} \quad(\mathrm{kPa})$ & 20,000 \\
Power function, $m$ & 60,000 \\
Poisson's Ratio, $v$ & 0.5 \\
Interface coefficient, $R_{\text {int }}$ & 0.35 \\
\hline
\end{tabular}

Table 2. The van Genuchten model parameters.

\begin{tabular}{cc}
\hline Parameter & Value \\
\hline Residual degree of saturation, $S_{r}(\%)$ & 4.86 \\
Saturated degree of saturation, $S_{S}(\%)$ & 100 \\
Saturated hydraulic conductivity, $k_{\text {sat }}(\mathrm{m} /$ day $)$ & 0.127 \\
Fitting parameter, $n$ & 1.950 \\
Fitting parameter, $\alpha$ & 2.130
\end{tabular}

variation from dry to fully saturated condition reasonably well. The mathematical formulation of the van Genuchten (1980) SWCC is shown by Equation (5) [7].

$$
S(\psi)=S_{r}+\left(S_{s}-S_{r}\right)\left[1+\left(g_{a}|\psi|^{g_{n}}\right)\right]^{g_{c}}
$$

where $S(\psi)$ is the degree of saturation, $\psi$ is the matric suction, $g_{n}$ is a fitting parameter which is a function of the rate of water extraction from the soil once air entry value has been exceeded, $g_{a}$ is a fitting parameter related to the air entry value of the soil, and $g_{c}\left(i . e ., g_{c}=\left(\frac{1-g_{n}}{g_{n}}\right)\right)$ is another fitting parameter. The hydraulic parameters of the soil used for the analysis are listed in Table 2, and the van Genuchten model is graphically presented in Figure 2.

In unsaturated soils, the coefficient of permeability is represented as shown in Equation (6) using the relative permeability $\left(k_{r e l}\right)$ and fully saturated permeability $\left(k_{\text {sat }}\right)$.

$$
k=k_{\text {rel }} \times k_{\text {sat }}
$$

The relative permeability is a function of the DoS of the soil and computed 


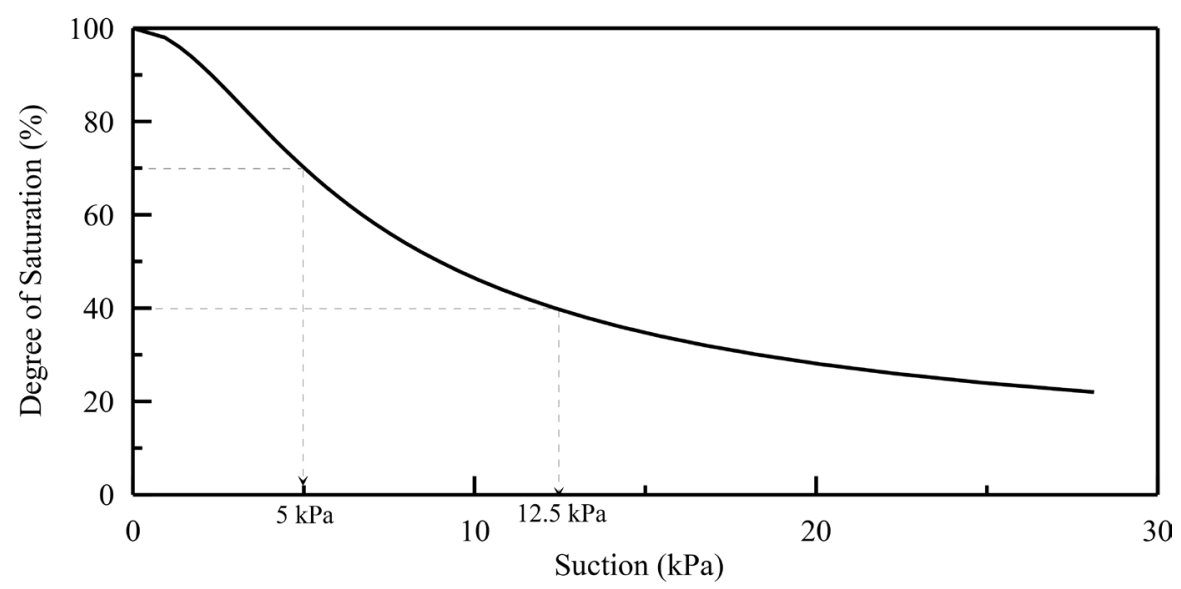

Figure 2. SWCC for the loamy sand.

using the soil water characteristic curve (SWCC) as shown in Equation (7). Additional details of the mathematical formulation and finite element discretization can be found in the PLAXIS 2D user manual [8].

$$
k_{\text {rel }}(\psi)=\frac{\left\{1-(\alpha \psi)^{n-1}\left[1+(\alpha \psi)^{n}\right]^{-m}\right\}^{2}}{\left[1+(\alpha \psi)^{n}\right]^{m / 2}}
$$

The effect of suction in the deformation behavior is more significant in fine-grained soils than the coarse-grained soils. However, the time taken for the water to infiltrate into the influence zone to induce settlement in the fine-grained soils is longer than the coarse-grained soils. Therefore, in this study, a Loamy sand that can induce a significant suction effect while allowing the water to flow through it within a reasonable time was used.

\section{Finite Element Model Development}

The two-dimensional plane strain formulation was used to model the footing-soil interaction in PLAXIS. The finite element model included a soil body with the properties of Loamy sand and a footing made up of non-porous elements with the rigidity properties of reinforced concrete. The simulation domain was spatially discretized using 15-node triangular elements. Size sensitivity and mesh sensitivity analysis were carried out to ensure that the user-controllable parameters (size of the domain and mesh) are not affecting the computed results. The simulation domain shown in Figure 3 had meshed finely with refinements around the footing where high-stress concentration is expected to improve the accuracy of the prediction. Three different widths $(B=1.5 \mathrm{~m}, 3.0 \mathrm{~m}$, and $4.5 \mathrm{~m})$ were used to investigate the effect of footing width on the settlement behavior under different loading conditions. The deformation boundaries were applied such that the deformation of the vertical sides against translation in the $\mathrm{x}$-direction and the base of the model against both $\mathrm{x}$ - and $\mathrm{y}$-directions were restrained. The flow boundaries were assigned to restrict the flow through the base, and the vertical sides of the domain. The rainfall and flooding were applied 

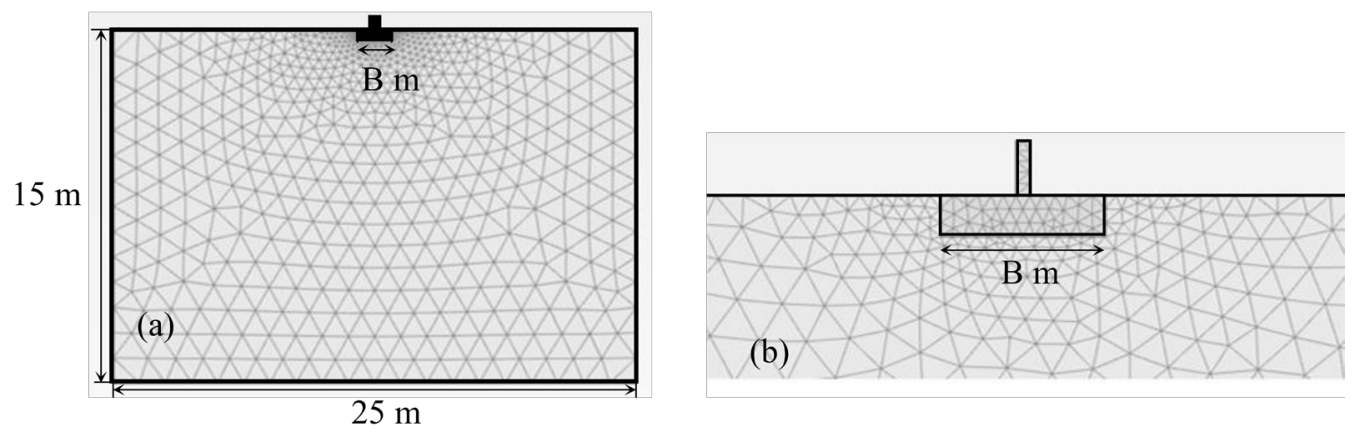

Figure 3. (a) Simulation domain with fine mesh and (b) mesh zoomed in-view of footing mesh.

using the discharge and head flow functions, respectively on the ground surface.

\subsection{Mechanical Load}

The Schmertmann's settlement equation along with the $N_{(60)}$ blow count values obtained from a local project in Albuquerque, New Mexico [9] was used to determine the mechanical load that can induce an initial settlement of $25 \mathrm{~mm}$ for a continuous footing embedded in a fully dried soil. The calculation yielded a mechanical load of $105 \mathrm{kN} / \mathrm{m}, 165 \mathrm{kN} / \mathrm{m}$, and $205 \mathrm{kN} / \mathrm{m}$ for the footing widths of $1.5 \mathrm{~m}, 3 \mathrm{~m}$, and $4.5 \mathrm{~m}$, respectively. The line loads were applied in the direction on the continuous footing. Initially, the mechanical load was applied with a dynamic load multiplier to increase the loading from zero to the determined loading at the end of one day, and then the load was maintained constant for the rest of the days. The settlement was elastic, and consolidation settlement was zero due to the nature of the soil used.

\subsection{Heavy Rainfall}

It is evident from the previous storms (i.e., the 2016 Hurricane Matthew (NC rainfall totals from Hurricane Matthew, 2016), the 2015 Columbia SC floods (South Carolina's Catastrophic Floods, 2016), and the 2005 Hurricane Katrina ([10] [11]) that the intensity of the heavy rainfall can range from $304 \mathrm{~mm}$ to 483 $\mathrm{mm}$ for a short duration. Therefore, total rainfall of $612 \mathrm{~mm}$ was applied for a period of six days. As shown in Figure 4, a rainfall intensity of $102 \mathrm{~mm} /$ day for six days was applied to analyze the effect of heavy rainfall on the behavior of the footing. As shown in Figure 4, additional eight days were provided for the water to infiltrate into the influence zone of the footing.

\subsection{Flood Data}

From the previous flood data (i.e., 2016 Hurricane Matthew, 2005 Hurricane Katrina, and 2015 Columbia SC floods), it is evident that the flood head ranged from 1 to $3 \mathrm{~m}$ and the flood water receded entirely after a week. These flood heads typically receded through runoff in local tributaries, wastewater systems, and infiltration into the soil. A dynamic head function shown in Figure 4 was used to model the flood head and the water was allowed to infiltrate during the 


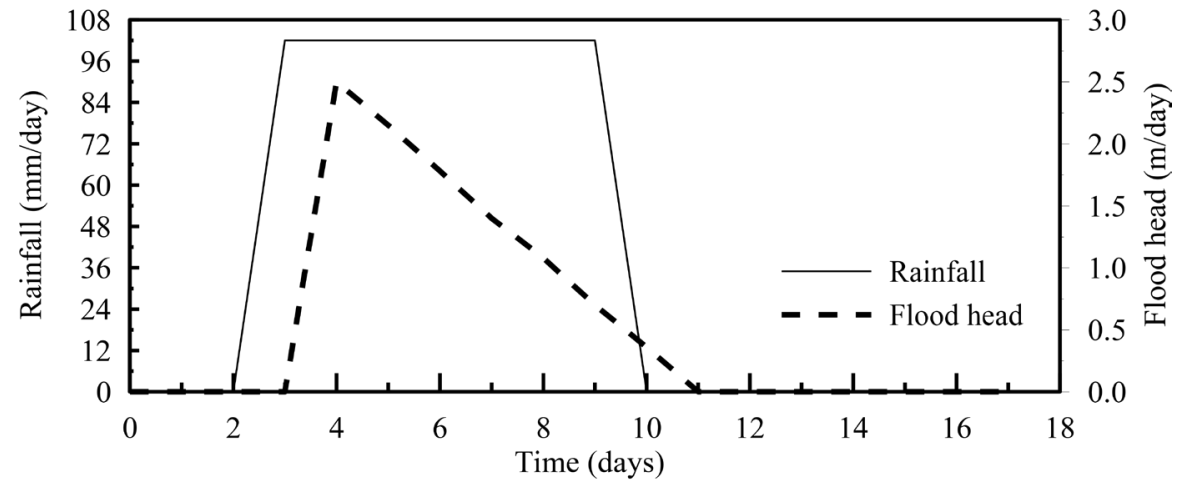

Figure 4. Rainfall and flood head-time history.

application of the flood head. The flood head was increased up to $2.5 \mathrm{~m}$ at the end of four days and receded to zero at the end of eleven days, as shown in Figure 4.

\section{Analyses and Results}

Parametric studies were carried out to investigate the effects of extreme hydrological events on the settlement behavior of the footing using PLAXIS 2D. Continuous footings with widths of $1.5 \mathrm{~m}, 3.0 \mathrm{~m}$, and $4.5 \mathrm{~m}$ were used to investigate the effect of footing widths on the settlement behavior. Initially, the parametric study was carried out to investigate the effect of initial DoS on the settlement behavior of the footing by applying mechanical loads. The analyses were carried out for initial DoS $4.86 \%\left(S_{r}\right)$ and $100 \%$ without considering the suction effect and $40 \%, 50 \%, 60 \%$, and $70 \%$ with considering the suction effect. Several initial DoS ranging from $40 \%$ to $70 \%$ were chosen for the rest of the studies as these DoS falls within the Loamy Sand's transition zone on the SWCC. The next parametric study was carried out to investigate the effects of heavy rainfall on the settlement behavior of the continuous footings. The heavy rainfall was applied for a period of six days and the water was allowed to infiltrate into the soil for another eight days numerically. Finally, the parametric study was carried out to analyze the effect of flood head on the settlement behavior of the footing. The flood head was raised up to 2.5 meters within one day and lowered to zero at the end of seven days by allowing the water to infiltrate into the soil. The details of the parametric studies carried out are given below.

\subsection{Analysis of Continuous Footing Subjected to Mechanical Loading}

Initially, the settlement behavior of the footing was analyzed by applying mechanical loads without any hydrological load (heavy rainfall or flooding). For the analysis, the mechanical loads of $105 \mathrm{kN} / \mathrm{m}, 165 \mathrm{kN} / \mathrm{m}$, and $205 \mathrm{kN} / \mathrm{m}$ were applied for the footing widths of $1.5 \mathrm{~m}, 3 \mathrm{~m}$, and $4.5 \mathrm{~m}$, respectively. Along with the mechanical loads, the initial DoS was varied to simulate completely dry, partially saturated, and completely saturated conditions. The computed settle- 
ment-time histories are shown in Figure 5(a) and Figure 5(b) for $1.5 \mathrm{~m}$, Figure 5(c) and Figure 5(d) for $3.0 \mathrm{~m}$, and Figure 5(e) and Figure 5(f) for $4.5 \mathrm{~m}$ wide continuous footings and the maximum settlement values are tabulated in Table 3. It should be noted that the effect of suction on the settlement behavior was not considered in the fully dry and saturated conditions for developing baseline understanding. A maximum settlement of $32.5 \mathrm{~mm}$ was induced when the footing was embedded in the fully saturated soil (Figure 4(a), Figure 4(c), and Figure 4(e)).
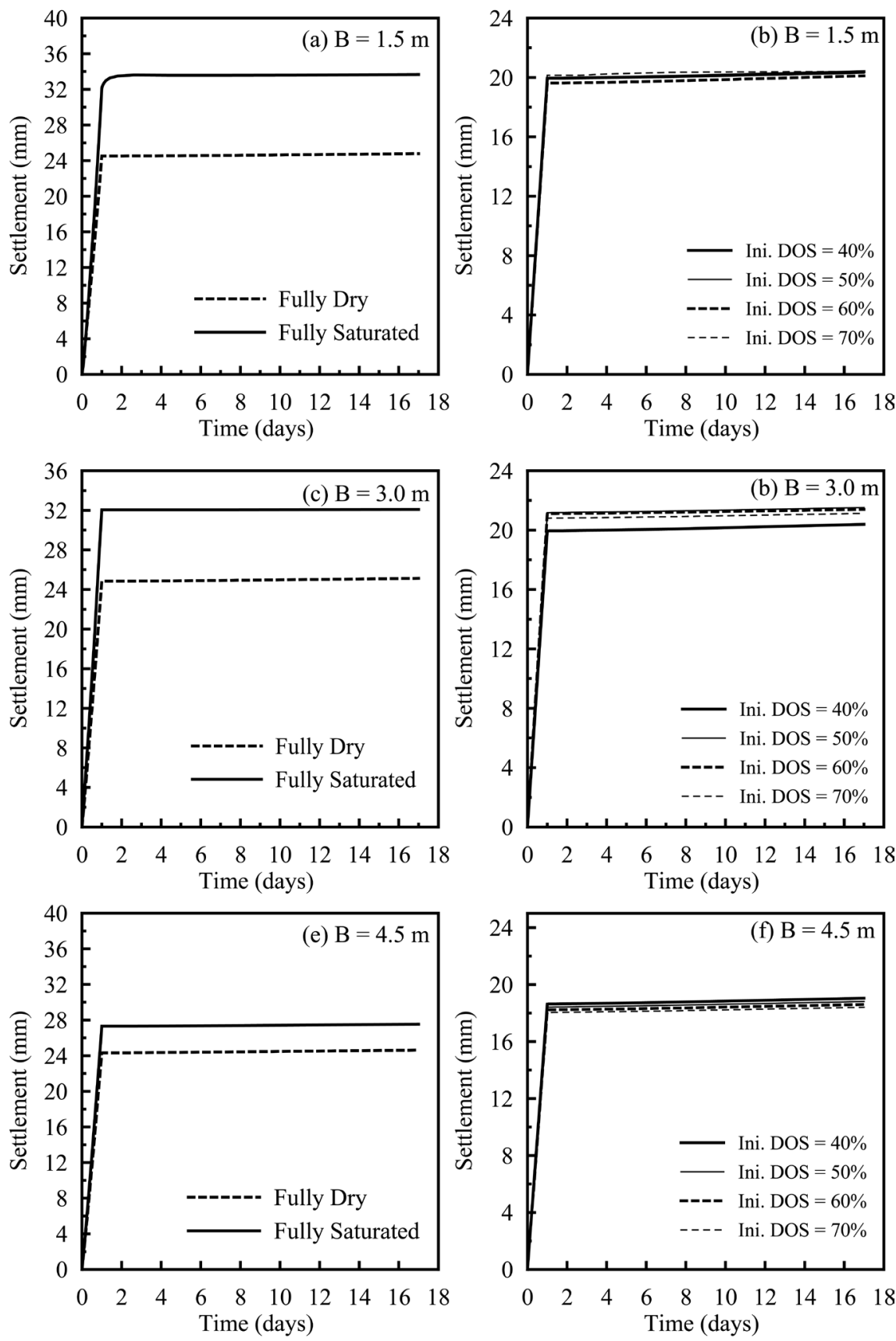

Figure 5. Settlement-time histories for fully saturated and dry soil for footing width (a) $1.5 \mathrm{~m}$, (c) $3.0 \mathrm{~m}$, and (e) $4.5 \mathrm{~m}$ and partially saturated soil with footing width (b) $1.5 \mathrm{~m}$, (d) $3.0 \mathrm{~m}$, and (f) $4.5 \mathrm{~m}$. 
Table 3. Computed maximum settlements for different initial DoS.

\begin{tabular}{cccc}
\hline \multirow{2}{*}{ Initial DoS (\%) } & \multicolumn{3}{c}{ Settlement (mm) } \\
\cline { 2 - 4 } & $\mathbf{B}=\mathbf{1 . 5} \mathbf{~}$ & $\mathbf{B}=\mathbf{3 . 0} \mathbf{~ m}$ & $\mathbf{B}=\mathbf{4 . 5} \mathbf{~ m}$ \\
\hline 0 (baseline-without suction) & 24.78 & 25.13 & 24.63 \\
40 (with suction) & 20.39 & 21.74 & 19.04 \\
50 (with suction) & 20.29 & 21.52 & 18.81 \\
60 (with suction) & 20.11 & 21.40 & 18.60 \\
70 (with suction) & 20.41 & 21.13 & 18.41 \\
100 (baseline-without suction) & 33.66 & 32.10 & 27.53 \\
\hline
\end{tabular}

Figure 4(a), Figure 4(c), and Figure 4(e) show that the soil settled approximately $25 \mathrm{~mm}$ when the loading was applied for the fully dry conditions. The results indicated that the settlements in fully dry and saturated conditions reached peak value within one day when the mechanical load was applied and remained constant for the rest of the days due to the sandy nature of the soil body. The initial DoS of $40 \%, 50 \%, 60 \%$, and $70 \%$ were used to consider the effect of suction on the settlement behavior of the footing. It is evident from Figure 5(b), Figure 5(d), and Figure 5(f) and Table 3 that the settlements for the partial DoS reduced as DoS increased for all the footings except for footing width of $1.5 \mathrm{~m}$ with $70 \%$ initial DoS. The settlement value increased from $60 \%$ to $70 \%$ for the footing width of $1.5 \mathrm{~m}$. The results showed that the increase in the DoS beyond $70 \%$ results in an increase in settlement of the footing. Ignoring suction and assuming the soil is completely saturated can lead to the overprediction of settlements.

\subsection{Analysis of Continuous Footing Subjected to Heavy Rainfall}

In this parametric study, the effect of heavy rainfall on the settlement behavior of the footing was analyzed by considering two possible cases. In the first case, the rainfall was applied on one side of the footing as shown in Figure 6(a), which represents the outside edge of the structure where the wetting front can only expand on the exposed side. In the second case rainfall on both sides of the footing as shown in Figure 6(b) was considered to represent the footings that are used for large signs and telephone posts. For both cases, initially a rainfall intensity of $102 \mathrm{~mm} /$ day was applied for six days. Then the water was allowed to infiltrate into the soil for another eight days, as shown in Figure 4. The effect of rainfall on the behavior of the footing was analyzed by evaluating the additional settlement that was induced due to the infiltration of the water into the influence zone of the footing.

Tables 4-6 show that the average additional settlement induced in the continuous footing due to the application of heavy rainfall ranged from $0.16 \mathrm{~mm}$ to $0.86 \mathrm{~mm}$. The results indicated that the differential settlement was higher when the rainfall was applied on one side of the footing with values ranging from 0.24 
Table 4. Settlements induced on the $1.5 \mathrm{~m}$ wide footing due to the heavy rainfall.

\begin{tabular}{|c|c|c|c|c|c|}
\hline \multirow{2}{*}{$\begin{array}{l}\text { DoS } \\
(\%)\end{array}$} & \multirow{2}{*}{$\begin{array}{c}\text { Initial } \\
\text { settlement } \\
(\mathrm{mm})\end{array}$} & \multirow{2}{*}{$\begin{array}{l}\text { Additional } \\
\text { settlement (Case } \\
\text { two) }(\mathrm{mm})\end{array}$} & \multicolumn{2}{|c|}{$\begin{array}{l}\text { Additional settlement from } \\
\text { (Case one) }(\mathrm{mm})\end{array}$} & \multirow{2}{*}{$\begin{array}{c}\text { Induced } \\
\text { Differential } \\
\text { settlement } \\
\text { (Case one) }(\mathrm{mm})\end{array}$} \\
\hline & & & $\begin{array}{l}\text { Left side of } \\
\text { footing }\end{array}$ & $\begin{array}{l}\text { Right side of } \\
\text { footing }\end{array}$ & \\
\hline 40 & 20.39 & 0.86 & 0.82 & 0.53 & 0.29 \\
\hline 50 & 20.29 & 0.53 & 0.55 & 0.30 & 0.25 \\
\hline 60 & 20.11 & 0.18 & 0.57 & 0.37 & 0.20 \\
\hline 70 & 20.41 & 0.16 & 0.45 & 0.11 & 0.30 \\
\hline
\end{tabular}

Table 5. Settlements induced on the $3 \mathrm{~m}$ wide footing due to the heavy rainfall.

\begin{tabular}{|c|c|c|c|c|c|}
\hline \multirow{2}{*}{$\begin{array}{l}\text { DoS } \\
(\%)\end{array}$} & \multirow{2}{*}{$\begin{array}{c}\text { Initial } \\
\text { settlement } \\
(\mathrm{mm})\end{array}$} & \multirow{2}{*}{$\begin{array}{l}\text { Additional } \\
\text { settlement (Case } \\
\text { two) }(\mathrm{mm})\end{array}$} & \multicolumn{2}{|c|}{$\begin{array}{l}\text { Additional settlement from } \\
\text { (Case one) }(\mathrm{mm})\end{array}$} & \multirow{2}{*}{$\begin{array}{c}\text { Induced } \\
\text { Differential } \\
\text { settlement } \\
\text { (Case one) }(\mathrm{mm})\end{array}$} \\
\hline & & & $\begin{array}{l}\text { Left side of } \\
\text { footing }\end{array}$ & $\begin{array}{l}\text { Right side of } \\
\text { footing }\end{array}$ & \\
\hline 40 & 21.74 & 0.71 & 0.71 & 0.42 & 0.29 \\
\hline 50 & 21.52 & 0.44 & 0.94 & 0.34 & 0.60 \\
\hline 60 & 21.40 & 0.44 & 0.45 & 0.23 & 0.22 \\
\hline 70 & 21.13 & 0.18 & 0.41 & 0.14 & 0.27 \\
\hline
\end{tabular}

Table 6. Settlements induced on the $4.5 \mathrm{~m}$ wide footing due to the heavy rainfall.

\begin{tabular}{cccccc}
\hline $\begin{array}{c}\text { Initial } \\
\text { DoS }(\%)\end{array}$ & $\begin{array}{c}\text { Initial } \\
\text { settlement } \\
(\mathrm{mm})\end{array}$ & $\begin{array}{c}\text { Additional } \\
\text { settlement (Case } \\
\text { two) }(\mathrm{mm})\end{array}$ & $\begin{array}{c}\text { Additional settlement from } \\
\text { (Case one) }(\mathrm{mm})\end{array}$ & $\begin{array}{c}\text { Induced } \\
\text { Differential } \\
\text { settlement }\end{array}$ \\
\hline 40 & 19.04 & 0.63 & 0.48 & 0.40 & Right side \\
(Case one) $(\mathrm{mm})$
\end{tabular}

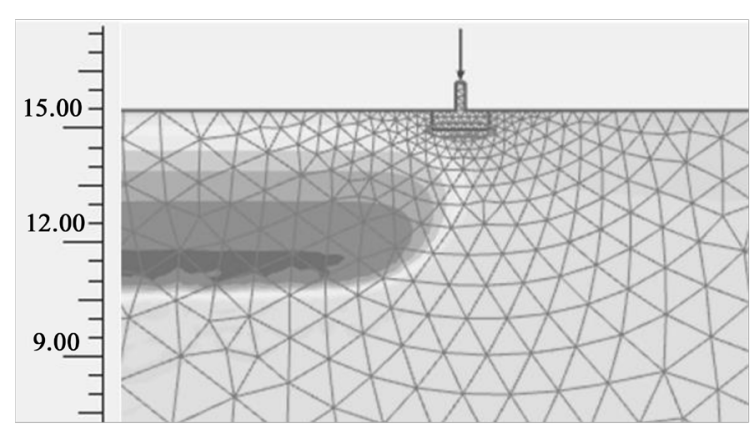

(a)

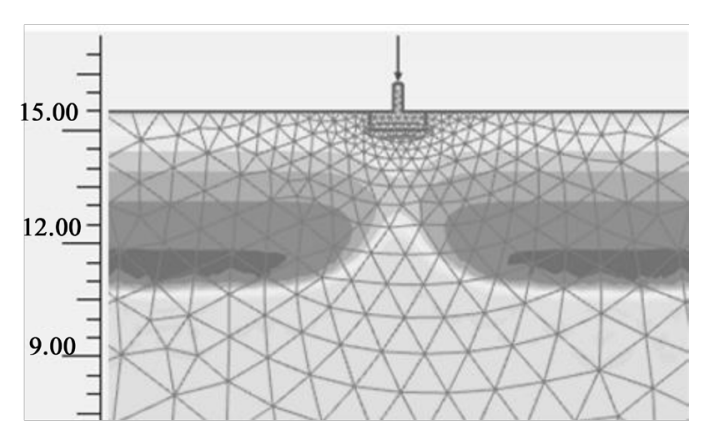

(b)

Figure 6. Wetting front for soil at 50\% DoS with heavy rainfall for (a) case one and (b) case two.

$\mathrm{mm}$ to $0.94 \mathrm{~mm}$. The maximum settlements of $0.94 \mathrm{~mm}$ and $0.6 \mathrm{~mm}$ were induced in case one and two, respectively when the footing with width $3.0 \mathrm{~m}$ was 
embedded in the soil with initial DoS of $50 \%$.

The extent of the wetting front due to the heavy rainfall ranged from 3 meters (2 times of footing width) for the initial DoS of $40 \%$ to 7.5 meters (5 times of footing width) for the initial DoS 70\%. Figure 6(a) and Figure 6(b) show the sample wetting front for both cases for an initial DoS 50\% at the end of 17 days. The extent of the wetting fronts in both cases was identical. The total extents of the wetting front ranging from partial to full coverage of saturation within the influence zone of the footing was four times the width of the footing.

Figures 5(a)-(c) show that the footing remained stable even after the immediate settlement at the end of one day under mechanical load. Once the rainfall was introduced, the instability was induced due to the decrease in the suction and effective vertical stress of the soil for both cases. The suction reduced to zero as the DoS increased to $100 \%$ when the wetting front proceeded down the soil. This induced higher pore water pressures and reduced the effective stress of the soil. An increase in the DoS to $100 \%$ lead to additional settlements as the confining pressure of the soil was lowered from the reduced effective vertical stress. The upper bounds of the Hardening Soil model stress-strain curve in Figure 1 decreased as the confining pressure decreased. This resulted in a reduction in stiffness and additional settlements. Figures 7(a)-(d) show the variation of DoS and suction with time for different initial DoS. Figures 7(a)-(d) are sufficient to represent both cases, since both cases had similar wetting fronts and the wetting fronts passed the benchmark depths simultaneously. The benchmarks were measured at the depths of $0 \mathrm{~m}$ ( $0.5 \mathrm{~m}$ from the ground surface), $1.5 \mathrm{~m}$, and $3.0 \mathrm{~m}$ from the bottom of the footing. Figures 7(a)-(d) can represent the variation of DoS and suction for all three footing widths as the size did not affect the hydraulic conductivity of the soil. The bottom of the footing, which is $0.5 \mathrm{~m}$ from the ground surface, was completely saturated for six days (duration of the heavy rainfall) regardless of the footing size and the initial DoS.

The wetting fronts reached faster to the depths of $1.5 \mathrm{~m}$ and $3 \mathrm{~m}$ below the footing when the initial DoS was high. Figures 7(a)-(d) show that the wetting front reached the $1.5 \mathrm{~m}$ benchmark in seven days for the initial DoS of $70 \%$, while it took 9.25 days for the wetting front to reach the $1.5 \mathrm{~m}$ benchmark for the initial DoS of $40 \%$. This illustrated that when the initial DoS is high, there are fewer pores to fill and the saturation occurs faster and the wetting front moves faster.

Figures 8(a)-(c) show that the wetting front on one side of the footing (i.e., case one) induced instability even after the removal of rainfall. In the case of case two the stability was regained when the heavy rainfall ended, as shown in Figures 8(e)-(f). Although the suction was regained (as shown in Figure 7) after ten days the induced settlement was not recovered. This is because the soil exhibited plastic behavior and settled permanently.

The settlement results in Tables 4-6 illustrated that the change in the DoS greatly affected the amount of settlement. The results indicated that the settlements 

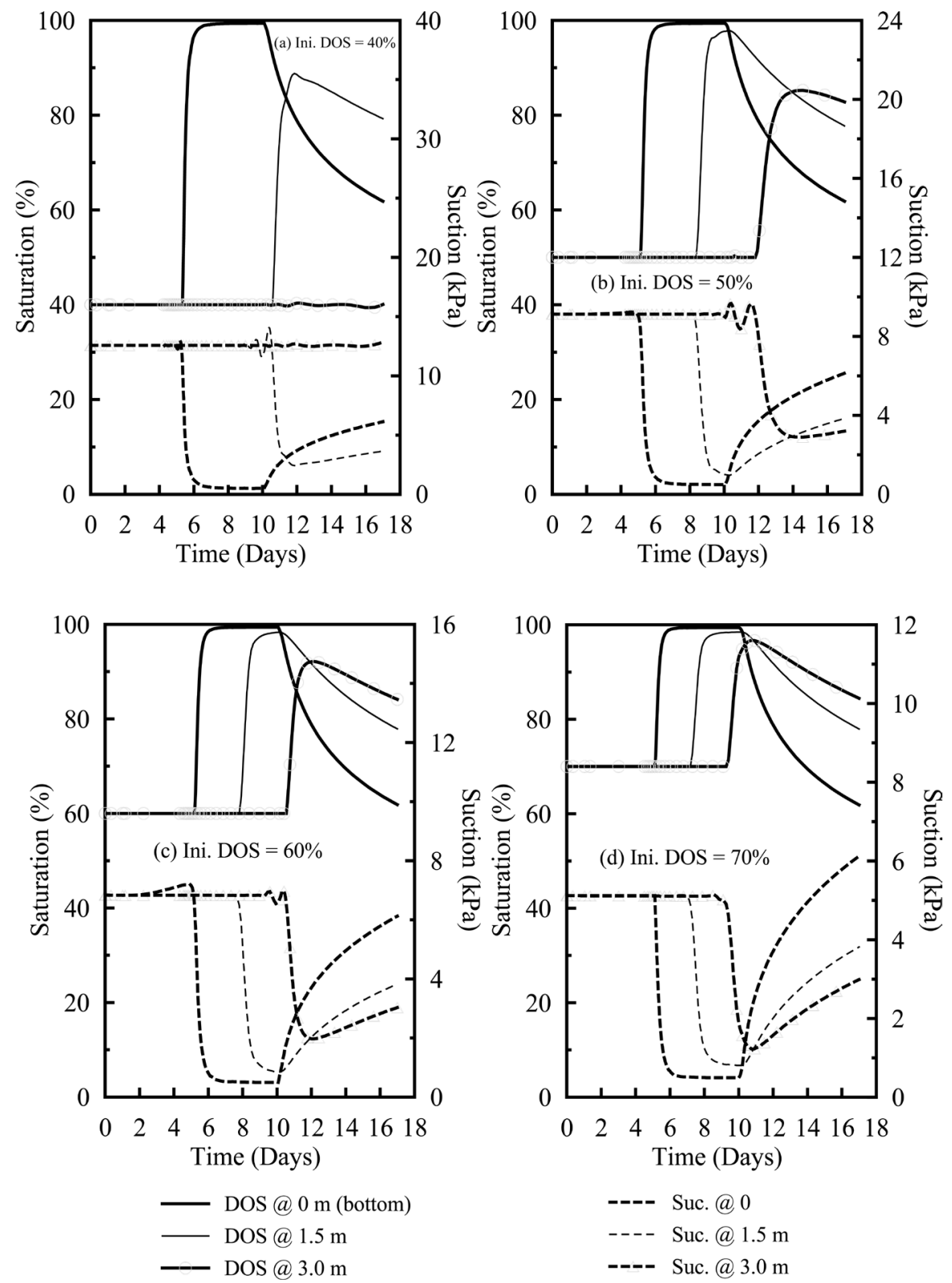

Figure 7. Saturation- and suction-time histories due to heavy rainfall at various depths

induced due to the heavy rainfall were higher when the initial DoS was low despite the shallower wetting front. This is because of the significant difference in the saturation contours within the influence zone before and after the rainfall. These deeper zones of complete saturation covered more of the stress within the influence zone but did not induce more settlement. As discussed previously, this resulted from the soil bodies with higher DoS, having higher initial unit weight.

The results indicated that the settlements induced by heavy rainfall were low and within the allowable settlement (less than $25 \mathrm{~mm}$ ). However, this was from a single heavy rainfall event and if heavy rainfall events are compounded over time, it could have damaging consequences on the serviceability of the superstructure. 

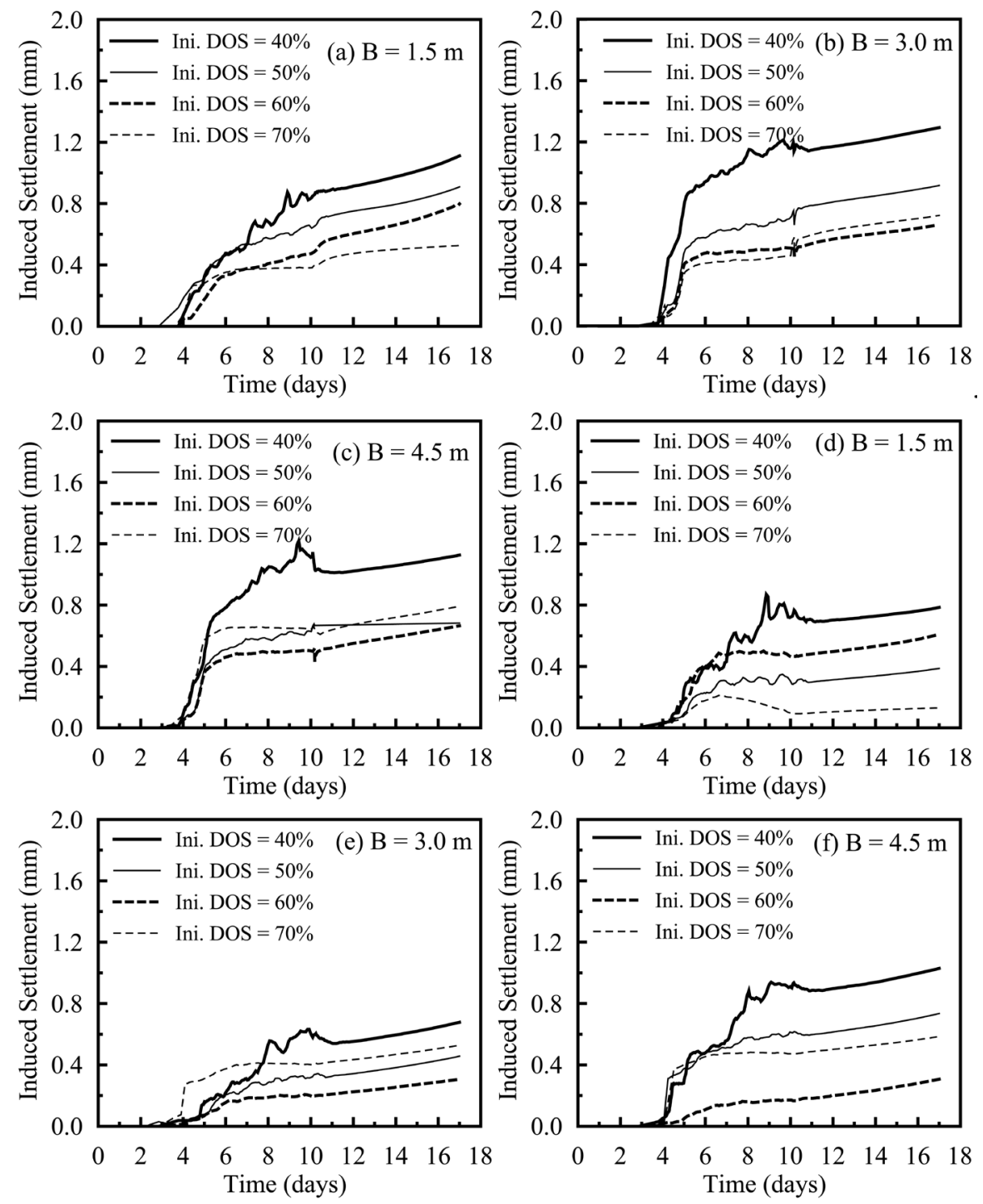

Figure 8. Heavy rainfall-induced settlement-time history for case one for (a) $1.5 \mathrm{~m}$, (b) $3.0 \mathrm{~m}$, and (c) $4.5 \mathrm{~m}$ wide continuous footing and for case two for (d) $1.5 \mathrm{~m}$, (e) $3.0 \mathrm{~m}$, and (f) $4.5 \mathrm{~m}$ wide continuous footing.

\subsection{Analysis of Continuous Footing Subjected to Flooding}

The third parametric study was carried out to analyze the effects of extreme flood events on the settlement behavior of the footing. Flood data from the 2016 Hurricane Matthew, the 2015 Columbia South Carolina floods, and the 2005 Hurricane Katrina were reviewed, and a flood head of 2.5 meters was imposed on the ground surface to simulate these flood events. The flood head was raised up from the ground surface to a height of $2.5 \mathrm{~m}$ in one day and subsequently lowered back to zero at the end of seven days by allowing the water to infiltrate into the soil, as shown in Figure 4. Similar to the previous study two cases were considered. In case one, the flood head was applied on one side of the footing, wherein case two the flood head was applied on both sides of the footing, as shown in Figure 10. This was performed for continuous footings of widths 1.5 
$\mathrm{m}, 3.0 \mathrm{~m}$, and $4.5 \mathrm{~m}$.

Figure 9(a) and Figure 9(b) illustrates that the depth of the wetting front for the flood condition extended much deeper than the heavy rainfall. The wetting front depths ranged from $6 \mathrm{~m}$ for the initial DoS of $40 \%$ to $10.75 \mathrm{~m}$ for the initial DoS of 70\%. This shows that half of the influence zone was fully saturated.

Also, the flood induced higher settlements when the initial DoS was higher as the initial unit weight of the soil before and after saturation was higher. In the case of low DoS, the increasing pore pressures due to the movement of the wetting front within the influence zone had more effect on the settlement. The models with low DoS had a larger drop in the suction due to the application of flood head. This is the reason for obtaining high settlements for the initial DoS of $40 \%$ compared to $70 \%$. Reduction in vertical effective stress and loss of suction led to total deformations of $26.95 \mathrm{~mm}$ to $42.99 \mathrm{~mm}$. These settlements were much larger than tolerable settlements for any structure that would utilize a shallow footing and would cause serviceability concerns for a structure.

Figures 10(a)-(d) show the variation of DoS and suction for the initial DoS $40 \%, 50 \%, 60 \%$, and $70 \%$ due to the application of a flood head of 2.5 meters. The extent of the wetting front and the time-history of the wetting front were identical for both cases. Therefore, Figures 10(a)-(d) represent both cases. The wetting fronts induced by flooding were much larger and deeper than the ones induced by the heavy rainfall. This is because the unsaturated hydraulic conductivity of the soil reached the saturated hydraulic conductivity sooner as the soil was in the fully saturated condition due to the continuous supply of water due to the flooding that was applied for eight days. This can be observed in Figures 10 (a)-(d) as the DoS of soil reached $100 \%$ and the suction dropped to zero and remained constant for the rest of the days. In the case of soil with the initial DoS of $40 \%$, the wetting front did not reach a depth of $3.0 \mathrm{~m}$ below the footing.

The results indicated that the depth below the footing played an important role in the settlement analyses. The presence of fewer free pores in the soils with a higher initial DoS allowed the soil to become fully saturated faster and the wetting front reached deeper. The results indicated that when the DoS of the soil was increased by $10 \%$, the wetting fronts passed the same point below the footing approximately 0.5 to 1 day faster.

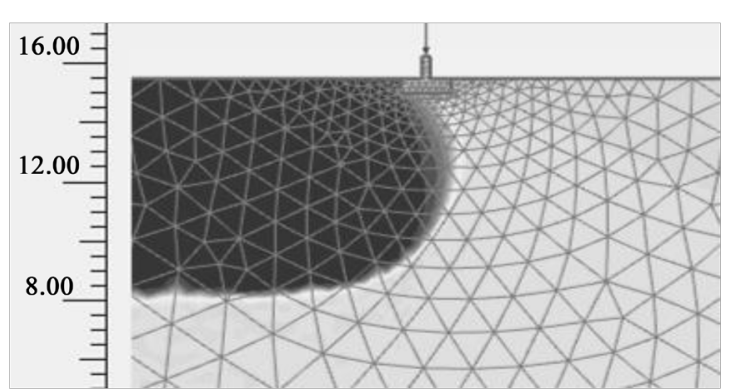

(a)

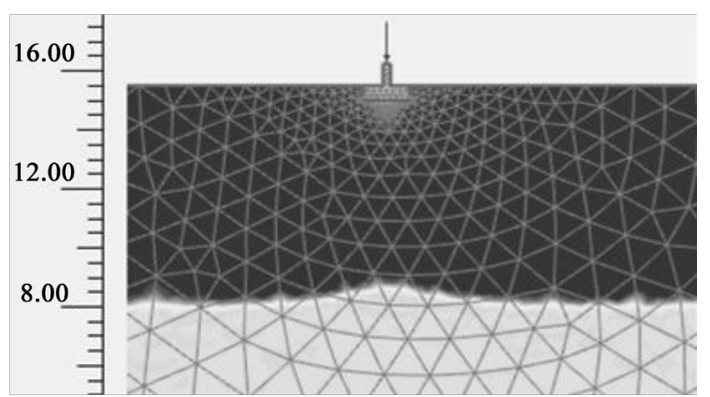

(b)

Figure 9. Wetting front for soil at 50\% DoS with flood conditions for (a) case one and (b) case two. 

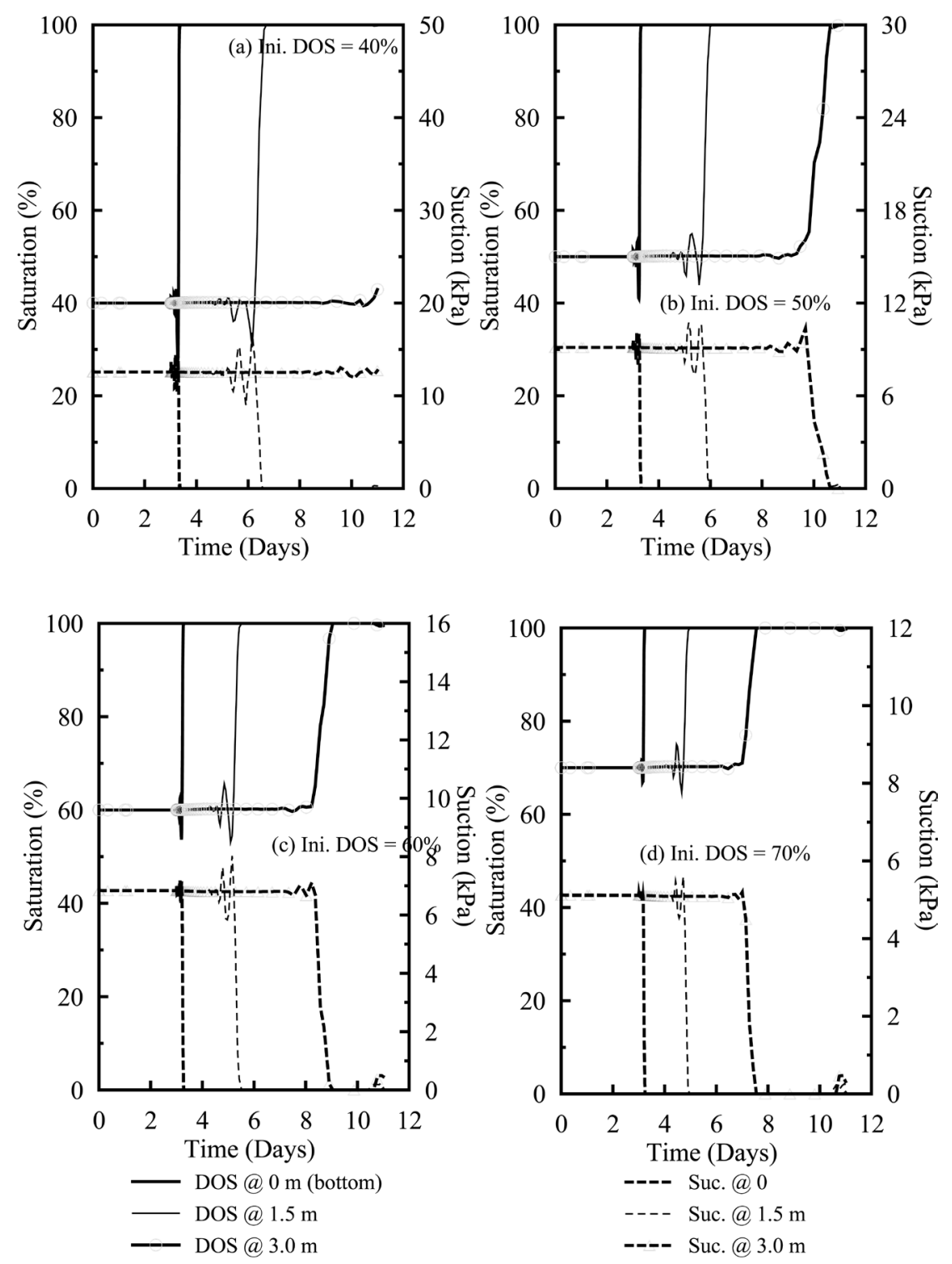

Figure 10. Saturation- and suction-time histories due to flooding at various depths.

Table 7. Settlements induced due to the application of flood on the $3 \mathrm{~m}$ wide footing.

\begin{tabular}{|c|c|c|c|c|c|}
\hline \multirow{2}{*}{$\begin{array}{c}\text { Initial } \\
\text { DoS (\%) }\end{array}$} & \multirow{2}{*}{$\begin{array}{c}\text { Initial } \\
\text { settlement } \\
(\mathrm{mm})\end{array}$} & \multirow{2}{*}{$\begin{array}{l}\text { Additional } \\
\text { settlement Case } \\
\text { two }(\mathrm{mm})\end{array}$} & \multicolumn{2}{|c|}{$\begin{array}{c}\text { Additional settlement Case } \\
\text { one }(\mathrm{mm})\end{array}$} & \multirow{2}{*}{$\begin{array}{c}\text { Induced Differentia } \\
\text { settlement } \\
\text { (Case one })(\mathrm{mm})\end{array}$} \\
\hline & & & Left side & Right side & \\
\hline 40 & 20.39 & 22.60 & 12.26 & 11.60 & 0.66 \\
\hline 50 & 20.29 & 21.96 & 11.92 & 11.31 & 0.61 \\
\hline 60 & 20.11 & 21.34 & 11.36 & 10.73 & 0.63 \\
\hline 70 & 20.41 & 20.10 & 10.61 & 10.22 & 0.39 \\
\hline
\end{tabular}

Tables 7-9 show the induced settlements for both cases due to the application of flooding. Additional settlements of $18.16 \mathrm{~mm}$ to $22.60 \mathrm{~mm}$ were induced for the case two. In the case of case one minimum of $6.07 \mathrm{~mm}$ (right side) and a 
Table 8. Settlements induced due to the application of flood on the $4.5 \mathrm{~m}$ wide footing.

\begin{tabular}{|c|c|c|c|c|c|}
\hline \multirow{2}{*}{$\begin{array}{c}\text { Initial } \\
\text { DoS (\%) }\end{array}$} & \multirow{2}{*}{$\begin{array}{c}\text { Initial } \\
\text { settlement } \\
(\mathrm{mm})\end{array}$} & \multirow{2}{*}{$\begin{array}{c}\text { Additional } \\
\text { settlement } \\
\text { Case two }(\mathrm{mm})\end{array}$} & \multicolumn{2}{|c|}{ Additional settlement Case one ( $\mathrm{mm})$} & \multirow{2}{*}{$\begin{array}{c}\text { Induced } \\
\text { Differential } \\
\text { settlement } \\
\text { (Case one) (mm) }\end{array}$} \\
\hline & & & Left side & Right side & \\
\hline 40 & 21.74 & 20.87 & 10.52 & 8.56 & 1.96 \\
\hline 50 & 21.52 & 20.17 & 9.65 & 7.71 & 1.94 \\
\hline 60 & 21.40 & 19.29 & 9.74 & 8.03 & 1.71 \\
\hline 70 & 21.13 & 18.65 & 9.30 & 7.67 & 1.63 \\
\hline
\end{tabular}

Table 9. Settlements induced due to the application of flood on the $1.5 \mathrm{~m}$ wide footing.

\begin{tabular}{|c|c|c|c|c|c|}
\hline \multirow{2}{*}{$\begin{array}{c}\text { Initial } \\
\text { DoS (\%) }\end{array}$} & \multirow{2}{*}{$\begin{array}{c}\text { Initial } \\
\text { settlement } \\
(\mathrm{mm})\end{array}$} & \multirow{2}{*}{$\begin{array}{c}\text { Additional } \\
\text { settlement } \\
\text { Case two } \\
(\mathrm{mm})\end{array}$} & \multicolumn{2}{|c|}{ Additional settlement Case one ( $\mathrm{mm}$ ) } & \multirow{2}{*}{$\begin{array}{c}\text { Induced } \\
\text { Differential } \\
\text { settlement } \\
\text { (Case one) (mm) }\end{array}$} \\
\hline & & & Left side & Right side & \\
\hline 40 & 19.04 & 19.93 & 9.83 & 6.79 & 3.04 \\
\hline 50 & 18.81 & 19.53 & 9.48 & 6.59 & 2.89 \\
\hline 60 & 18.60 & 18.83 & 9.12 & 6.38 & 2.74 \\
\hline 70 & 18.41 & 18.16 & 8.54 & 6.07 & 2.47 \\
\hline
\end{tabular}

maximum of $12.26 \mathrm{~mm}$ (left side) additional settlements were induced. Tables 7-9 also show that approximately $0.39 \mathrm{~mm}$ to $3.04 \mathrm{~mm}$ of differential settlement were induced for case one.

Figures 11(a)-(f) show that once the flood water level began to rise the footing became more unstable as the settlement increased rapidly. This is because of the settlement that was induced by the hydrostatic load due to the flooding. This load had a greater influence on case two than case one. Figures 12(a)-(f) show that after the settlements reached a peak value at the maximum height of the flood, the footing experienced some rebound as the hydrostatic pressure of the flood head was lowered. This was a coupled effect where lowering of the pressure head caused the soil to rebound, but the increased DoS of the soil was reducing the suction to zero and lowering the effective vertical stress of the soil. This resulted in permanent deformation of the soil underlying the footing that was not recoverable. The amount of rebound that the footings experienced ranged from $6.99 \mathrm{~mm}$ to $8.78 \mathrm{~mm}$ for case two and $3.56 \mathrm{~mm}$ to $4.11 \mathrm{~mm}$ for case one. The results indicated that not all the settlements were induced by the soil saturation but also due to the hydrostatic loading of the flood head.

\section{Conclusion}

The performance of shallow continuous footings subjected to extreme hydrological events was evaluated using the coupled Geotechnical-Hydrological finite element software PLAXIS 2D. Infiltration of water during heavy rainfall and flooding saturated the soil to a great extent and caused a reduction in suction 

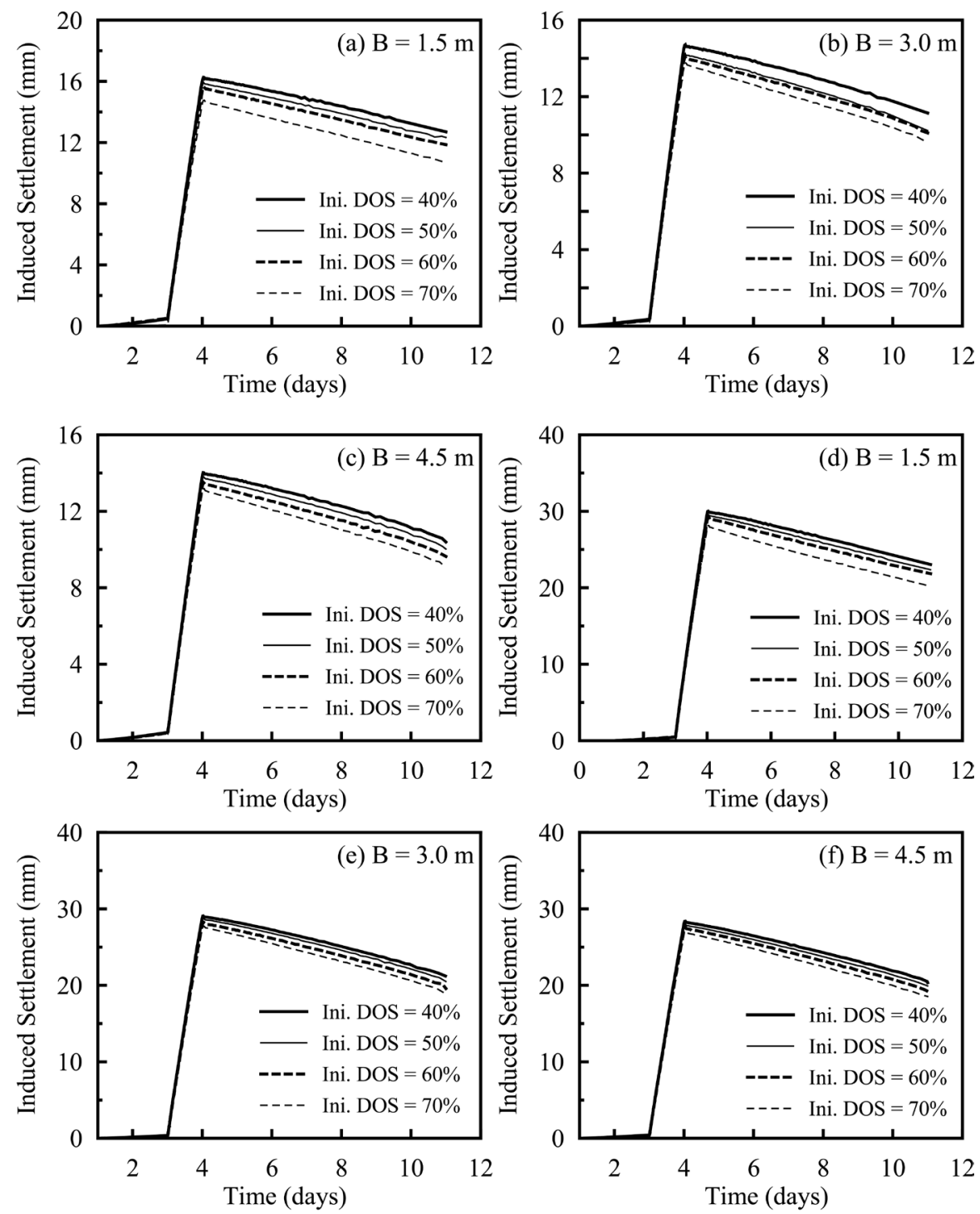

Figure 11. Flood induced settlement-time history for extreme flood for case one (a), (b), and (c) and case two (d), (e), and (f)

and thereby reduced the vertical effective stresses. The settlements induced by the flooding were higher than the heavy rainfall. Although small amount of additional settlements was induced by heavy rainfall, when there is compounded rainfall over time, these deformations will lead to damage to the footing and the superstructure. The reason behind the flooding to cause higher settlements than the heavy rainfall was that along with the reduction in the soil suction, additional hydrostatic flood load was applied on the soil. The settlements induced by the flooding exceeded the allowable settlement of $25 \mathrm{~mm}$, resulting in footing failure. The results of this study showed that heavy rainfall and flooding can be harmful to the serviceability of a structure. The results indicated that the design of continuous footings overestimates the footing design parameters compared with the actual condition of the site locations, even for extreme rainfall events. Based on the results, the matric suction, which is a significant parameter of 

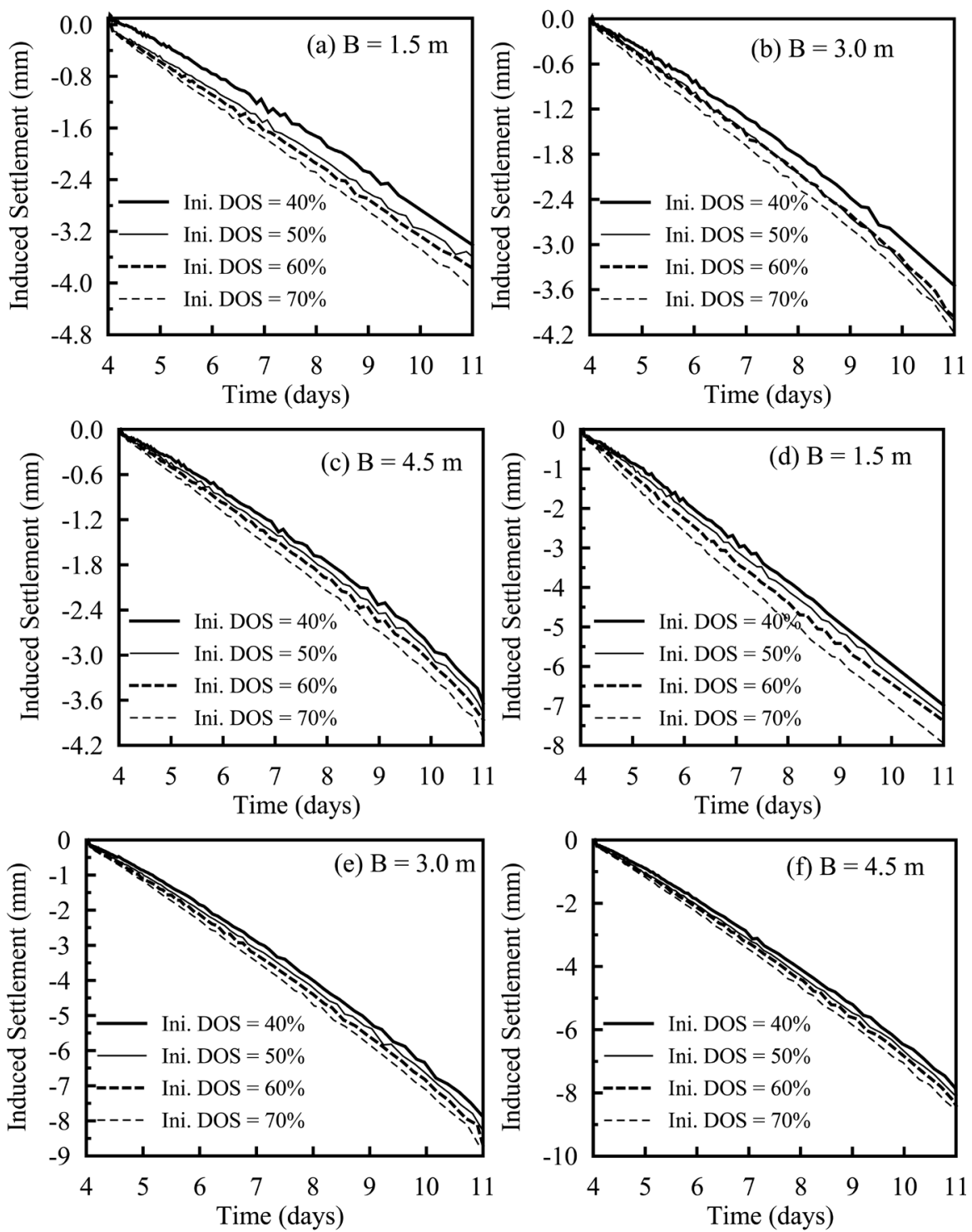

Figure 12. Flood recede induced settlement-time history for case one (a), (b), and (c) and case two (d), (e), and (f).

partially saturated conditions, had a significant effect on the settlement of the continuous shallow footing subjected to extreme hydrological events. Future research should be conducted on other types of footings to indicate if footing type affects the behavior when subjected to extreme hydrological events.

\section{Acknowledgments}

Critical comments and suggestions by the anonymous reviewers greatly helped to improve the quality of the manuscript.

\section{Conflicts of Interest}

The authors declare no conflicts of interest regarding the publication of this paper. 


\section{References}

[1] Vanapalli, S.K. and Mohamed, F.M. (2007) Bearing Capacity of Model Footings in Unsaturated Soils. Experimental Unsaturated Soil Mechanics, 112, 483-493. https://doi.org/10.1007/3-540-69873-6 48

[2] Kim, Y., Jeong, S. and Kim, J. (2016) Coupled Infiltration Model of Unsaturated Porous Media for Steady Rainfall. Soils and Foundations, 56, 1071-1081.

https://doi.org/10.1016/j.sandf.2016.11.010

[3] Mahmoudabadi, V. and Ravichandran, N. (2019) Design of Shallow Footing Considering Site-Specific Rainfall and Water Table Data: Theoretical Framework and Application. International Journal of Geomechanics, 19, Issue 7. https://doi.org/10.1061/(ASCE)GM.1943-5622.0001432

[4] Oh, W.T., Vanapalli, S.K. and Puppala, A.J. (2009) Semi-Empirical Model for the Prediction of Modulus of Elasticity for Unsaturated Soils. Canadian Geotechnical Journal, 46, 903-914. https://doi.org/10.1139/T09-030

[5] Oh, W.T. and Vanapalli, S.K. (2012) Modelling the Settlement Behavior of In-Situ Shallow Footings in Unsaturated Sands. Proceedings of the Geo-Congress, Oakland, 25-29 March 2012, 2542-2551. https://doi.org/10.1061/9780784412121.260

[6] Schanz, T., Lins, Y. and Vanapalli, S.K. (2010) Bearing Capacity of a Strip Footing on an Unsaturated Sand. Proceedings of the 5 th International Conference on Unsaturated Soils, Barcelona, 8 September 2010, 1195-1220.

[7] van Genuchten, M. (1980) A Closed-Form Equation for Predicting the Hydraulic Conductivity of Unsaturated Soils. Soil Science Society of America Journal, 44, 892-898. https://doi.org/10.2136/sssaj1980.03615995004400050002x

[8] PLAXIS (2019) PLAXIS 2D Reference Manual. Bentley Systems International Limited, Dublin.

[9] Schmertmann, J.H. (1978) Guidelines for Cone Penetration Test. (Performance and Design) No. FHWA-TS-78-209 Final Report (to the U. S. Department of Transportation Federal Highway Administration (HDV-22)). Washington DC, 148 p.

[10] Dunerman, M.J. and Anderson, M.I. (2015) Geotechnical Engineering Report Proposed O'Rielly Auto Parts Store. Albuquerque, NM: Terracon Consultants, Inc., 1-43

[11] Wiltgen, N. (2015) South Carolina's Catastrophic Floods Caused by One of the Most Prolific Rainfall Events in Modern US History.

https://weather.com/news/news/south-carolina-historic-flood-rainfall-record-extre me 